\title{
On the Cover of this Issue: In-situ Strain Field Measurement and Mechano-Electro-Chemical Analysis of Graphite Electrodes via Fluorescence Digital Image Correlation by H. Xie, W. Yang, Y. Kang, Q. Zhang, B. Han, and W. Qiu
}

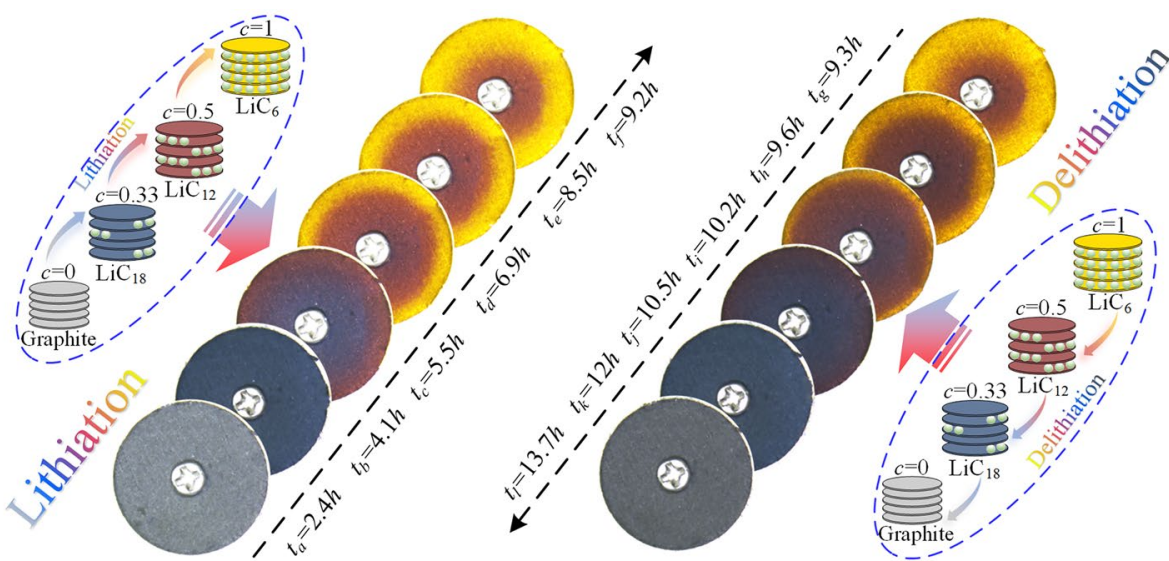

In-situ Strain Field Measurement and Mechano-Electro-Chemical Analysis of Graphite Electrodes via Fluorescence Digital Image Correlation by H. Xie, W. Yang, Y. Kang, Q. Zhang, B. Han, and W. Qiu 